\title{
humanidades
}

Revista humanidades

Enero-junio, 2016•Volumen 6, número 1 • ISSN 2215-3934•pp. 1-16

\section{Las Fiestas de San Fermín en España: ¿Pasión o violencia?}

DOI: http://dx.doi.org/10.15517/h.v6i1.25033

\section{Jiaoyue Liu}

Profesora de español en la Universidad Ciudad de Pekín, China.

Correo electrónico: leticia_1126@126.com 
Hay algunos estudios sobre las Fiestas de San Fermín que han ofrecido una base teórica. Liu Chuan (2009) señala que, para los españoles, el honor es más importante que la vida. Eso explica por qué la fiesta lleva tantos años en la historia y aún continua. Shi Xuping (2001) cree que cada año, numerosos jóvenes celebran esta fiesta peligrosa porque se puede despertar el espíritu de aventura. Sun Enhe (2012) señala que Hemingway dijo una frase: "Ven a España, es que allí hay la fiesta más maravillosa del mundo". En el último año del gran escritor, este dijo a un periodista: "Nunca puedo ir a España más. No quiero ser enterrado bajo la tierra española porque España es un lugar en que la gente lucha por la vida”. Wu Ruozeng (2011) opina que la corrida de toros es demasiado cruel e injusta para los animales. Es un juego de muerte. Li Shiyi (2002) piensa que no quiere decir bien o mal sobre cancelar o conservar la fiesta, solo espera que los participantes puedan volver a casa a salvo.

Se espera que con este ensayo se pueda conocer más sobre la cultura festival de España y promover el interés en aprender el idioma. Ya que existe la discrepancia sobre cancelar o conservar los sanfermines en la sociedad, se considera que es importante que cada vez más estudiosos den importancia a este tema y que se puedan hacer más investigaciones en este campo.

Las Fiestas de San Fermín son conocidas también como los sanfermines. Esta fiesta se celebra en honor de San Fermín, patrón de Pamplona. Entonces, era al principio una fiesta religiosa. Los sanfermines tienen mucho que ver con la corrida de toros. En el siglo XIV, para llevar fácilmente a los toros desde los corrales de fuera de Pamplona hasta la plaza, a la gente se le ocurrió una buena idea: correr delante de los animales

\section{Introducción}

\section{Las Fiestas de San Fermín}
El origen y el desarrollo de las Fiestas de San Fermín


en vez de detrás, así guiándolos al destino. Eso es lo que conocemos hoy como "el encierro". Así pues, podemos decir que efectúan el encierro con propósito de la corrida. En 1591, conmemorar al patrón y el encierro se hicieron en los mismos días. Con el tiempo, el encierro se hizo el auge de los sanfermines, en lugar de la corrida. Así dio origen a las Fiestas de San Fermín.

Los sanfermines, fiestas propias y tradicionales de España, fueron cada día más conocidas por todo el mundo, gracias al famoso escritor norteamericano Ernest Miller Hemingway. Fue en 1923 cuando él llegó a España y experimentó la fiesta por primera vez. Desde entonces, se enamoraba perdidamente del encierro, de la corrida y de todo elemento de los sanfermines. Luego visitó Pamplona, por Sanfermín, en 1924, 1925... 9 veces en total. Como un gigante literario, creó unas obras que trataban de la corrida de toros, por ejemplo, Death In The Afternoon y The Sun also Rises (editada en España como Fiesta). Sobre todo, al obtener el Premio Nobel de Literatura en 1954, todo el país ya conocía los sanfermines. Afectadas y emocionadas por sus excelentes obras, cada vez más personas de distintos países acuden a Pamplona en julio para presenciar y celebrar esta fiesta maravillosa. Es así que las fiestas de San Fermín y su encierro han llegado a tan altas cotas de popularidad internacional.

Las Fiestas de San Fermín comienzan el 6 de julio y terminan el 14 de ese mes. Se celebran en el noreste de España, en Pamplona, la capital de Navarra. La inauguración se realiza en la Plaza del Ayuntamiento el 6 de julio. El lanzamiento del cohete a las doce del mediodía es la señal del inicio de la fiesta. Se puede oír el grito ritual de entre la multitud: “Pamploneses, ¡Viva San Fermín, Gora San Fermín!”. Mientras tanto la

\section{La celebración y las costumbres de las Fiestas de San Fermín}


gente se viste con ropa blanca y lleva un pañuelo rojo en la muñeca, en el bolsillo o en la mano. El pañuelo rojo es la vestimenta típica de las fiestas de San Fermín. Se dice que se origina de una costumbre religiosa en honor al patrón San Fermín.

El encierro se celebra a las ocho de la mañana, del 7 al 14 de julio. Es una carrera delante de seis toros salvajes y seis cabestros. La carrera es de 875 metros; consiste en siete tramos: el tramo Santo Domingo, el Ayuntamiento, el Mercaderes, el Estafeta, el Telefónica, el Callejón y la Plaza de Toros. Cuando todos los toros llegan ya a la plaza y entran en sus corrales, es la hora de acabar el encierro.

A las 6:30 de la tarde empieza la corrida de toros en la plaza. La corrida de toros es el patrimonio cultural de España. Durante una corrida, tres toreros tienen que lidiar contra seis toros: un torero con el primero y el cuarto toro; otro con el segundo y el quinto; y el último con el tercero y el sexto. Una corrida de toros tiene su propio orden. Se divide en tres partes o tercios: Varas, Banderillas y Muerte. Además, hay dos suertes: la de Capote y Muleta. Después de un espectáculo excelente, uno de los toreros debe llevar el toro a la muerte.

Por fin, la gente se reúne en la Plaza de Ayuntamiento a medianoche del día 14, para asistir al rito de despedida. Es costumbre que cada uno lleva una vela encendida con un vaso de plástico alrededor y va cantando la canción de despedida: "pobre de mí, pobre de mí, que se han acabado las fiestas de San Fermín”. Entonces las Fiestas de San Fermín del año se

\section{Pasión de las Fiestas de San Fermín}

Las características de los españoles acaban. 
Sin duda alguna, se puede decir que los sanfermines son una fiesta de calle, llenos de gente, alegría, velocidad, carnaval y pasión. Eso está relacionado con las características de los españoles, o, mejor dicho, el carácter de esta nación.

Como es conocido, los españoles son entusiastas y extrovertidos. Si se intentara describir a España con un color, ninguno será mejor elección que el rojo. El rojo simboliza el sol, el entusiasmo, la pasión y un corazón latiendo. Se puede ver en muchos aspectos: el autor Lin Da (2007) escribió en su obra Notas de viajes a España: “有人说 , 假如你去西班牙人的家 , 千万别说你喜欢什么, 他马上就会抓起来作为礼物送给你; 也有 人说, 西班牙人, 你只要给他一个好天气, 再往他手里塞一把吉他 ，他就总是对生活很满意，我想，大概还要加一个卡门。”. [Unos dicen que si visitas a una familia española, recuerda que nunca le haces darse cuenta de lo que te gusta, es que lo tomará inmediatamente y te lo regalará, otros dicen que a los españoles, con sólo ofrecerles un tiempo bueno y darles una guitarra, siempre están satisfechos con la vida. Y pienso que es mejor añadir una Carmen]. Además, los factores culturales españoles reflejan el entusiasmo y la pasión de los españoles.

El flamenco, como la tarjeta de España, igual que la corrida de toros, es un baile cálido, alegre, elegante y energético. Tal vez cuando se menciona una guapa española, pasará en nuestra mente una imagen bailando el flamenco. Por eso, incluso las mujeres españolas son alegres, abiertas y cuentan con una belleza salvaje. 
No cabe duda de que los españoles son valientes y de espíritu aventurero.

Les gusta hacer las cosas aventuradas pero significativas, aunque hay ciertos peligros y riesgos. Se puede decir que ellos son optimistas y buenos en la innovación. Por ejemplo, los Reyes Católicos financiaron a Cristóbal Colón hacer la navegación hacia el Oeste por el Atlántico, dándole los

medios materiales y humanos. Por supuesto que era una acción aventurada e imaginable en aquel entonces. Pero esta aventura les resultó el descubrimiento del Nuevo Mundo, la acumulación de la riqueza hasta el alzamiento de la monarquía hispánica. Sin el coraje, los toreros no se atravesarían a presentarse en la plaza y lidiar contra los toros de una forma artística y entretenida. Sin la pasión, el último miércoles del mes de agosto en Buñol de Valencia, no se celebraría la Tomatina en que los participantes se arrojan tomates los unos a los otros como librando una batalla de tomates. Sin el espíritu de aventura, en los Sanfermines no haría tantos ciudadanos españoles que participan en el encierro y corren delante de los animales salvajes. Pase lo que pase, todo esto ha reflejado claramente las características típicas españolas.

Los Sanfermines no solo son una fiesta, sino también una mezcla de carnaval, bacanal y cachondeo. Antes del encierro, la multitud se reúne en los bares o calles y se acostumbran tomar bebidas con muchos grados de alcohol, disfrutando el favorecido "como no", por la generosa absorción de la bebida. Aunque hay bastante borrachera colectiva en toda esquina de la ciudad, nadie se queja porque eso es el verdadero "ambientillo sanferminero". No hay molestia, tristeza ni cansancio, solo piensa "hoy es Sanfermín".

\section{Los españoles son valientes $\mathbf{y}$ aventurados}

\section{La apariencia de la pasión de la fiesta}

\section{Los encierros locos}


Cuando empieza el encierro, llega el auge de la fiesta. La calle está llena de gente: los participantes, los visitantes, los viajeros, los borrachos, etc. Cada uno lleva la ropa blanca con un pañuelo rojo en el cuello. Cuando ellos cantan la canción “A San Fermín pedimos, por ser nuestro patrón, nos guíe en el encierro, dándonos su bendición”, parece que se está en medio de una marea roja. Es un espectáculo tan imponente, atractivo y emocionante que ni siquiera se desea mover los ojos.

Con el aviso del cohete, los toros se sueltan del corral y los corredores se encentran en la mirada y dirección. A continuación, todos tienen que correr lo más rápido posible delante de los animales. Se siente como una carrera excitativa y peligrosa, porque se está escapando de los toros. A veces cuando un toro cae en la tierra, un sonido gigantesco del cuerpo de 600 kilos turba la multitud. Durante el encierro, los corredores corren con un entusiasmo loco, unos tocan a los toros, unos se caen y se levantan para seguir, otros corren detrás de los toros. Se pueden oír los cantos, gritos, silbidos y palabrotas en la calle, ruidosos así, pero con mucha pasión.

Como una parte esencial de la fiesta, la corrida de toros es esperada por una gran cantidad de personas. Cuando el torero aparece en la plaza, con la ropa típica roja o amarilla brillante bajo el sol, los espectadores le reciben con aplausos fuertes y gritos. Después llega el momento de mostrar el encanto y la habilidad. El torero no se preocupa por matar al toro, sino que trae una representación de girar, evadir y provocarlo. Esas acciones peligrosas reflejan la característica individual, la inteligencia, la fuerza, el coraje y la belleza del torero. Todo el mundo se preocupa, se anima, se divierte y grita. Parece que no hay nada emocionante más que la corrida.

\section{La corrida de toros emocionante}

\section{La apariencia de la violencia}
Violencia de las Fiestas de San Fermín 


\section{Jiaoyue Liu}

Como es conocido, cada moneda tiene dos lados. Aunque los sanfermines son excitativos y pasionales, existen muchas violencias que podemos imaginar. A lo largo de la historia han producido numerosos accidentes y agresiones a los toros y a la gente.

En el encierro, a mucha gente le gusta enfurecer a los toros para hacer la carrera más interesante y peligrosa. A decir verdad, enfadar a estos animales salvajes no es prohibido. No obstante, como dice la frase: Nunca poner el placer en el sufrimiento de los demás. La gente se habitúa a maltratar a los toros durante el encierro, por ejemplo, pegándole a los animales o lanzando zumo de chile encima de los ojos de toros. Liu Chuan (2009) escribió en uno de sus artículos: “奔牛活动同样是不人道的, 因为奔跑者会拉扯公牛的 尾巴, 用脚踢它们, 并且让牛在恐㜔的情绪中奔跑”, “动物们饱受折 磨, 而且没有人有权仅仅是为了在节日上取乐就这样对待动物。”. [E1 encierro es tampoco inhumano, es que los corredores pueden tirar la cola de los toros, darlos un puntapié con fuerza y los dejan correr atropelladamente, los toros se sufren mucho, y nadie tiene derecho a tratar a los animales así solamente por divertirse en la fiesta].

Además, se describe la corrida de toros de las tardes, la realidad es más cruel. Los toreros tienen que maltratar a los toros poco a poco de diversas formas. Las tres partes de la lidia de los toros revelan cómo los llevan a la muerte: después de que el presidente ordena el inicio de la corrida, dos picadores montados a caballo deben clavar una vara en el lomo del toro para que se debilite y pierda de fuerza. En el segundo tercio, los banderilleros tienen que clavar tres pares de banderillas en el lomo del toro. A continuación, el torero clava la espada en el lomo y el toro, con cuerpo 
sangrado, muere rápidamente frente a todo el mundo. En este momento, el torero consigue los aplausos, el grito y el respeto de los espectadores. También puede recibir las orejas del toro que ha matado como trofeo, incluso el rabo, si la faena ha sido perfecta y maravillosa. Dicen que en España cada año al menos 40000 toros se matan por la corrida. Así, a lo largo de la historia de la corrida de España, ¡cuántos toros murieron a manos de los matadores!

Hay más de 200000 personas al año que acuden a Pamplona desde diferentes países. Cuando tanta gente se reúne en la calle de la carrera del encierro, de 875 metros, y tienen que correr seguidos los animales salvajes que corren a la velocidad de 40 kilómetros a la hora; llega el peligro. Es normal que la gente se caiga y que desafortunadamente, uno de los toros los alcance. Si este animal está excitado o enfadado, le chocará con sus piernas o le corneará con sus cuernos. Según datos, desde el año 1924 hasta 2002, 14 personas murieron y 200 más se hirieron durante el encierro.

Entre los 125 toreros conocidos en últimos 300 años, más de 40 de ellos murieron por la clava de los cuernos en la plaza de toros. E1 21 de mayo de 2010, un torero español Julio Aparicio, le ocurrió una tragedia en la plaza titulada La Ventas Arena en Madrid. Perdió el equilibrio y se cayó cuando lidiaba contra el toro, y este le corneó y le traspasó la mandíbula. Fue un momento sangriento y violento que asustó a todo el mundo. Por eso, en esta fiesta popular es posible que en un momento la situación sea divertida, mientras que segundos después aparezca sangre en el cuerpo de una persona. Es razonable, entonces, que las fiestas de los sanfermines se consideren violentas.

\section{La gente sufre heridas y muertes}


Frente a estos toros es inevitable la violencia, puesto que la violencia es la naturaleza de todos los animales salvajes. Además, normalmente los toros elegidos para la corrida son los machos feroces y crueles, de especie norteafricana. Tienen los genes puros y buenos. Desde el nacimiento, son cuidados por criaderos profesionales. Cuando tienen cinco años, ya son de 400 o 500 kilos de peso. Los que corren en el encierro y lidian en la plaza son de ese tamaño. Aquí hay un sentido común sobre los toros. Mucha gente cree que los toros se ponen excitados al ver el rojo, es la imagen clásica cuando un torero sortea con el capote rojo. En realidad, los toros son daltónicos y no se sienten emocionados por ningún color, sino por los objetos que se mueven. Por eso, cuando se corre delante de ellos, este seguirá al objeto sin cesar. Así, sin darse cuenta, una persona puede ser agredida, es innegable la naturaleza violenta del animal salvaje.

Aunque los toros son violentos por naturaleza, ellos no comen a la gente. Como dice la frase: los que no ofendan se respetan, pero los que ofendan se ofenderán. Eso lo lleva bien incluso a los animales. En la fiesta, las personas son tan cálidas, alegres y con tanta pasión que de vez en cuando prefieren enfurecer a los toros. Ese es el problema. Para hacer el encierro más interesante, a veces la gente aguza los cuernos de los toros e incluso les hace daño. Los tocan, les pegan, los agarran de la cola, les lanzan algo duro, les ponen el zumo de chile, como se mencionó arriba. Los toros tienen que defenderse y vengarse por haberles hecho el daño. Si la gente no los hubiera maltratado, los animales no se enfadarían y no sucederían tantas violencias.

La ideología desarrollada de la humanidad es responsable de la violencia en los sanfermines. Actualmente, se piensa que los seres humanos deben

\section{Los motivos de la violencia}


vivir en armonía junto con los animales. Es inmoral maltratar o matar a los animales e incluso prohibido cazar los que están en peligro de extinción. Se puede ver en calle y en la televisión muchos eslóganes y anuncios de servicio público para proteger los animales. Eso es una ideología avanzada

de la humanidad. En la antigüedad, el Coliseo Romano era el símbolo de la civilización romana. Hace cientos o miles de años, nadie pensó que maltratar a las mujeres era una violencia doméstica. Antes los españoles nunca dudaron la importancia de las fiestas de San Fermín. Con el tiempo, todo ha cambiado.

En los sanfermines, cuando la mayoría está celebrando y entreteniéndose, se pueden ver muchos conservacionistas haciendo protesta con pancartas en español e inglés. Ellos señalan "Basta de mantanzas”, "Stop”, "Help the bull”. El año pasado el 5 de julio, algunos conservacionistas se disfrazaron de los toros, estaban desnudos de pie en los ataúdes de papel para protestar la celebración de los sanfermines. Decían en sus pancartas "Stop the bloody bullfight, no a las corridas de toros", "Pamplon: sangre, tortura y muerte", "Bulls die bloody, deaths in Pamplona". Además, la gente de otros países se ha metido a protestar contra la fiesta. Ellos opinan que los animales son miembros de la naturaleza y tienen derecho a sobrevivir y protegerse. El encierro y la corrida les han quitado su derecho y los hacen sufrir mucho.

En los últimos años, cada vez más personas han participado en la manifestación de protesta. Su propósito se limita a cancelar la corrida de toros y las Fiestas de San Fermín. En Cataluña, los miembros de la Plataforma Prou, formada por activistas por los derechos de los animales,

\section{Cancelar o conservar las Fiestas de San Fermín}

\section{Cancelar la fiesta con violencia y sangre}


dirigieron un movimiento animalista catalán. Movilizaron a más de mil personas por una causa común y recogieron más de 180000 firmas. Se trata de una Iniciativa Legislativa Popular para abolir las corridas de toros en esta comunidad. Bajo la presión de los activistas, el 28 de julio de 2010, el Parlamento Autónomo Catalán aprobó la resolución, por 68 votos a favor y 55 en contra, que a partir de 1 de enero de 2012 estarían prohibidas las corridas de toros en Cataluña. Así que Cataluña era la primera en prohibir las corridas en España. Elena Escoda, uno de los miembros de la Plataforma Prou, dijo: "Esta abolición genera un precedente que deberá ser imitado (...). Aún queda mucho por hacer”. Sobre la abolición, la actriz Brigitte Bardot opinó que había sido una victoria de la democracia y de la dignidad sobre la crueldad.

Con tantas voces opuestas en la sociedad española e internacional, es una tendencia debatir la fiesta entre la pasión y la violencia. ¿A dónde van las Fiestas de San Fermín? Eso es una pregunta difícil y vale la pena pensarlo bien.

Aunque las actividades en la fiesta son peligrosas, violentas y crueles, será difícil prohibir esta fiesta en toda España absolutamente. Cuando mucha gente dice no a las Fiestas de San Fermín, tanto en España como en otros países, se debe considerar la importancia festival en la historia, la economía

\section{Conservar la cultura festival tradicional de España} y la cultura tradicional de España. En este punto, la mayoría está a favor de conservar los sanfermines.

Los sanfermines ya tienen cientos años en la historia española. Se han establecido profundamente en la vida diaria, la sociedad y la cultura de este país. La palabra "toro" o "torero" se ha conocida como el símbolo de España. La Selección de fútbol de España, el campeón del Mundial de 2010 
en Sudáfrica y de la Copa de Europa en 2012, es nombrado como "el torero" por los demás. "La Canción de torero" de la ópera Carmen ha sido una canción esencial en la historia musical mundial. También se puede ver lo importante que es en la vida cotidiana a través de los refranes españoles. "Pan y toros" significa que bastan con estas dos cosas y nada más

importante. "Toro muerto, vaca es" quiere decir que, en el fondo, los toros no son tan fuertes como se imagina. "Llamar al toro desde la barrera, eso lo hace cualquiera", "al toro por el cuerno, y al hombre por la palabra y a la mujer por el elogio". Estos son los refranes usados a menudo. Gracias a la fiesta, Ernest Miller Hemingway escribió Death In The Afternoon y The Sun also Rises y Picasso creó muchas obras sobre la corrida de toros. La fiesta es la inspiración de los artistas.

Se sabe que cada año más de 200000 personas van a Pamplona a los sanfermines. Es notable que la llegada de los visitantes puede estimular el consumo del turismo, la comida y la cultura. Es la fiesta la que ha ofrecido una gran cantidad de empleos para los pamploneses. Por eso, conservar los sanfermines es favorable para la economía española.

Se ha analizado esta fiesta típica en diversos aspectos. Por un lado, las

\section{Conclusión} Fiestas de San Fermín son pasionales, y, por otro lado, son violentas. Algunos están a favor de la fiesta, y otros opinan lo contrario. Por eso, cancelar o conservar los sanfermines se ha convertido en un foco de debate en todo el mundo.

En mi opinión, las Fiestas de San Fermín no se deben cancelar. En primer lugar, se trata de una fiesta típica y tradicional de España, que ha reflejado 
la historia, la cultura, las costumbres y el carácter de este país. Al hablar de China, decimos que la Fiesta de la Primavera constituye la más típica y representativa, lo mismo ocurre con los sanfermines para España. Podemos imaginarnos lo importante que es la fiesta para los españoles. Por eso, cancelarla equivale abandonar la cultura nacional de España.

Un país que ha perdido su cultura nacional es un pueblo sin carácter, o mejor dicho, sin alma. Se puede decir que, sin los Sanfermines, España no sería España. En segundo lugar, aunque Cataluña es un ejemplo al abolir las corridas de toros en España, no creo que esta decisión sea el detonante para que otras regiones hagan lo mismo en los últimos años. Estoy convencida de que hasta hoy día, las Fiestas de San Fermín aún cuentan con un gran encanto y atractivo y tienen su valor de existir. Cada año tanta gente acude a Pamplona a celebrar la fiesta, eso prueba que los sanfermines están llenos de vigor.

Asimismo, no se deben ignorar los efectos económicos que implica dicha la fiesta. No vale la pena abolirla silo para satisfacer a los animalistas y poner en riesgo la economía y la gran cantidad de empleos. Por último, creo que la pasión y la violencia dependen de las opiniones de la gente, o sea, algunos lo consideran violento, al contrario, los otros lo creen pasional. Para los que celebran la fiesta con su propia voluntad, se entretienen mucho y disfrutan de la pasión. No obstante, para los animalistas y los que sienten miedo a la lucha y a la sangre, sin duda, esta fiesta les parece violenta. Pero los animalistas son pocos, en comparación con todo el mundo. Su opinión negativa no es capaz de decidir el destino de la fiesta.

Los sanfermines nos facilitan conocer el carácter nacional y la cultura festival de España. También favorecen el aprendizaje del idioma. Creo que 


\section{Las Fiestas de San Fermín en España...}

cada día más personas los prestarán atención y tendrán sus propias ideas sobre cancelar o conservar las Fiestas de San Fermín.

Aranburu, M. (2008). "Los Sanfermines de Pamplona: escenario y taller de la memoria folclórica". En Jentilbaratz, 11, pp. 197-223. Recuperado de: http://www.euskomedia.org/PDFAnlt/jentil/11/11197223.pdf

Fiestas de San Fermín en Pamplona, AA Alberdi, Euskal-Erria, 1886: págs. $65-67$

Goikoetxandia, A. \& Martínez. J. (1989). "Perspectiva de las fiestas de San Fermín de Pamplona”. En Cuadernos De Etnología y Etnología De Navarra, 21, pp. 97-108

Hua Xiaojing. (s. f.). Decir "no" a las corridas de toros es difícil

[Mensaje de un blog]. Recuperado de:

http://bbs.tiexue.net/post_6252930_1.html

Jiang Linlin. (30 de julio de 2012). Una especie de festival de alegría silvestre llamada España. Shenzhen Daily. Recuperado de: http://news.enorth.com.cn/system/2012/07/30/009735776.shtml

Liu. (27 de septiembre de 2011). No muere torero a quien toro le perfora la garganta en Barcelona. Diario de Beijing. Recuperado de: http://sports.sohu.com/20110927/n320688227.shtml 
López-Guillén, J. (29 julio de 2010). Cataluña dice NO a las corridas. 20 minutos. Recuperado de:

http://estaticos.20minutos.es/edicionimpresa/madrid/10/07/MADR _29_07_10.pdf

Ollaquindia, R. (1981). 100 años de carteles de las fiestas y Ferias de San Fermín (1882-1981). Pamplona: Caja de Ahorros de Navarra.

Viñes, H. (1988). "Las Fiestas de San Fermín entre lo teatral y lo cotidiano". En Investigaciones semióticas II: lo cotidiano y lo teatral. Universidad de Oviedo, Servicio de Publicaciones, pp. 463470.

Recibido: 18-enero-2016

Aceptado: 11-febrero-2016

Todos los derechos reservados. Universidad de Costa Rica. Esta revista se encuentra licenciada con Creative Commons Reconocimiento-NoComercialSinObraDerivada 3.0 Costa Rica. (CC BY-NC-SA 3.0 CR)

Correo electrónico: humanidades@ucr.ac.cr Sitio web: http://revistas.ucr.ac.cr/index.php/humanidades 